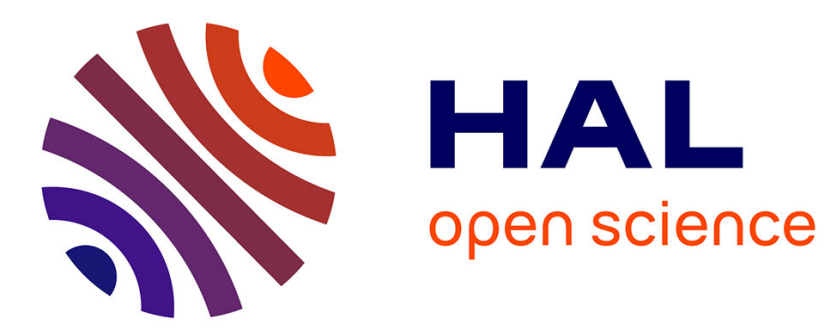

\title{
Maintenance schedules as boundary objects for improved organizational reliability
}

\author{
Stéphanie Tillement, Jan Hayes
}

\section{To cite this version:}

Stéphanie Tillement, Jan Hayes. Maintenance schedules as boundary objects for improved organizational reliability. Cognition, Technology and Work, 2019, 21, pp.497-515. 10.1007/s10111-018-0530y . halshs-02065500

\section{HAL Id: halshs-02065500 \\ https://shs.hal.science/halshs-02065500}

Submitted on 12 Mar 2019

HAL is a multi-disciplinary open access archive for the deposit and dissemination of scientific research documents, whether they are published or not. The documents may come from teaching and research institutions in France or abroad, or from public or private research centers.
L'archive ouverte pluridisciplinaire HAL, est destinée au dépôt et à la diffusion de documents scientifiques de niveau recherche, publiés ou non, émanant des établissements d'enseignement et de recherche français ou étrangers, des laboratoires publics ou privés. 


\title{
Maintenance schedules as boundary objects for improved organizational reliability
}

\author{
Stéphanie Tillement, \\ Phone: (+33) 251858555 \\ Email: Stephanie.tillement@imt-atlantique.fr
}

Jan Hayes, 2

Email jan.hayes2@rmit.edu.au

1 IMT Atlantique, LEMNA, UBL, La Chantrerie, 4 rue Alfred Kastler, B.P. 20722 44307, Nantes cedex 3, France

2 RMIT University, PO Box 2476, Melbourne, VIC, 3001 Australia

Received: 22 March 2018 / Accepted: 15 September 2018

\section{Abstract}

Organizations that manage complex technologies use planning in various forms to determine priorities and structure work with the goal of controlling both production and system reliability. In addition to this purely functional view of planning, there is a social dimension that also has important system safety implications. Drawing on 53 semi-structured interviews with workers at a nuclear fuel processing plant, this paper addresses the role of the schedule for planned maintenance work. Characterizing the schedule as a boundary object highlights the socio-material dimension of high reliability organizing. It sheds light on the negotiation that takes place at the boundary between five worker groups around the schedule, which allows cooperation without the need for consensus thanks to the interpretive flexibility. Diversity of views is acknowledged, but resolved sufficiently. A 'reliable' schedule is one that is accurate enough to facilitate necessary conversations without providing unnecessary constraints. It is a balance between what should be brought to light and what should deliberately be left in the shadows. Yet, the possibility for the schedule to act as a boundary object and to support interdepartmental coordination and organizational reliability depends on organizational and occupational conditions. When managers see the schedule as an object of control, they seek to impose additional standardization. Taken to the extreme, introducing rigidity into the system is aimed at organizational invariance that HRO researchers warn is not the key to reliable operations. The role and legitimacy of planners is also discussed, as a safeguard against the schedule becoming a fantasy plan. 
Keywords

Reliability

Boundary objects

Maintenance

Planning

Nuclear

Schedules

\section{Introduction}

Protecting the public and workers from accidents resulting from complex technologies is a system-wide undertaking in which various groups of actors have differing interests and functions (Milch and Laumann 2018). This creates a range of interfaces or boundaries within organizations and also between organizations. These 'interstices' are where errors occur (Bourrier 2005). A critical interface in process plant is that between operations and maintenance. The ambiguous relationships between these two groups impact organizational reliability (Bourrier 1996). They are structurally and functionally interdependent, but have different objectives and function on opposite timeframes, since carrying out maintenance tasks may stop production. Maintenance is thus perceived by production as a "necessary pain" whose duration must be reduced to the minimum through strict planning of activities. Bourrier's work is one of few studies that investigates the link between the nature of maintenance/production relationships and organizational reliability, i.e. prevention of major accidents.

This paper draws on research conducted in a nuclear fuel processing plant to investigate the role of the planned maintenance schedule. As an artefact of planning processes, a study of the role of schedules allows a better understanding of interdepartmental (Windischer et al. 2009) and interorganizational coordination vis-à-vis organizational reliability. The focus here is on the role of maintenance and the interface between this activity and the social worlds of other related actors. Further, organizations are increasingly under pressure to do more with less, which puts interfaces under even more pressure (Starbuck and Farjoun 2005). A typical managerial response in this environment is to increase efforts focused on planning to try to maintain safety, but to do it more efficiently. Organizations that "don't plan are seen as ineffective, poorly managed, irresponsible or sometimes just plain dumb" (Clarke 1999, p. 1). Reliable planning can be conceptualized as a key aspect of overall system reliability (Schulman 2012). Planning is conceptualized as a key management activity linked to complexity and the need to take into account multiple views to sustain reliable performance.

In this case, the emblematic object of planning, the schedule, is viewed as a boundary object that sits at the interfaces between five social worlds-maintenance, production, planners, contractors and management—and thus mediates the relationships between these 
groups. As such, the schedule has both functional and symbolic roles and so ultimately a significant impact on organizational reliability. Specific research questions are:

- In what ways does the schedule act as a boundary object between the five social worlds present?

- How does this symbolic role of the schedule impact organizational reliability?

- What organizational and professional conditions impact whether the schedule takes on this symbolic role and supports reliable performance?

In general organization theory, the concept of a boundary object, originally developed by Star and Griesemer (1989), has proven to be a useful way to consider how the tension between different actors and viewpoints at work is resolved. Boundary objects are "artefacts... involved in the collection, management and coordination of knowledge which is subsequently distributed" (Trompette and Vinck 2009, p. 3). Importantly, such knowledge can vary across different social worlds. As Star and Griesemer also discovered, boundary objects provide a way of working whereby, "consensus is not necessary for cooperation nor for successful conduct of work" (1989, p. 388). This is an important feature of the schedule at the nuclear plant where diverse views are accommodated and resolved sufficiently for action to occur, even if overall consensus is not obtained. A key point of contention is the extent to which maintenance work is made more visible and explicit, and thus subject to both scrutiny and control. In this way, the concept of a schedule as a boundary object provides a useful mechanism to understand the relationship between such plans and accident prevention that goes beyond a study of the schedule's overt organizing function.

\section{Maintenance planning, organizational reliability and boundary objects}

Investigations into the causes of major disasters have often shown that maintenance issues are a key factor. Problems include cost cutting and so reduction in maintenance effort [e.g. Texas City refinery fire (Baker 2007) and San Bruno pipeline failure (Hayes and Hopkins 2014)] and issues with interface management between maintenance and production [e.g. Piper Alpha (Cullen 1990) and the Glenbrook rail accident (McInerney 2001)]. In contrast to this, effective high reliability organizations (HROs) have been found to value maintenance activities. They are preoccupied with failure, seeing thorough analysis of all small failures as essential for learning since they are indicators of overall system health (Weick and Sutcliffe 2015). Maintenance departments in effective HROs therefore have a much more central role than in traditional organizations and are seen as key actors in the development of mindfulness (op.cit.). The experience of maintenance personnel is valued for the breadth of understanding of organizational strengths and weaknesses that it brings (Bourrier 1996). 
In complex socio-technical systems, maintenance and production exist as separate departments with their interactions controlled by planning processes. Given that maintenance is also key for overall system safety, this raises two significant theoretical questions. What is the link between planning and organizational reliability? What processes are at work at the boundaries between maintenance and other social worlds, in particular production?

According to Weick and Sutcliffe (2015), high reliability organizing requires an infrastructure that supports sensemaking, continuous organizing and adaptive managing (p. 21). A preoccupation with plans and planning appears to conflict with mindfulness, since it tends to make people act with some rigidity, operate on automatic pilot and mislabel unexpected problems as familiar, which is likely to worsen them. The disaster literature seems to confirm this vision: both Vaughan (1996) and Starbuck and Farjoun (2005) underscore from the analysis of Challenger and Columbia accidents that ongoing attention to production planning is a determinant of risk taking during projects.

Despite its proven contribution to efficiency, planning is often considered as a low level activity (Clarke 1999) and the schedule as a banal tool. In this view, planning does not rely on special skills and does not deserve much effort or attention. It consists mainly of the apparently simple description of a succession of tasks, in a logic of anticipation with a strong focus on control. As Mintzberg has noted, "perhaps the clearest theme in the planning literature is its obsession with control—of decisions and strategies, of the present and the future, of thoughts and actions, of workers and managers, of markets and customers" (1994, p. 201). This conventional way of theorizing planning focuses on anticipation, rationalization of work and formal modes of organization. Efforts are made to minimize uncertainty through standardization and few degrees of freedom available to people carrying out the plans (Windischer et al. 2009).

Other research takes a more sociological and situated view of system planning and organizational reliability (Roe and Schulman 2016; Schulman 2012; Suchman 1987) that goes beyond only control. In this view, plans can be a resource for action and adapted to the requirements of the situation and to contingencies, and so contribute to organizational resilience. From analysis of the normal functioning of a complex system (electrical network), Schulman (2012) proposes that planning for reliability has three key aspects: (1) identifying work that needs to be done to make the plant reliable; (2) determining how that work should best be organized; (3) balancing conflicting requirements (e.g. environmental, economic or reliability improvement).

Reliable planning is part of the process of planning for reliability and its key role is planning for surprises, which is more difficult. It refers to the degree to which the process of planning is conducted with protection against errors. Reliable planning can help in managing the expected as well as the unexpected, by enabling to detect and avoid errors, such as errors of risk avoidance, of omission, of optimism or of underestimating 
uncertainty (Schulman 2012). A crucial question related to reliable planning is how planning is sensitive to the needs of field personnel, particularly given the distribution of work between multiple stakeholders. Planning is a long process that goes from the construction of a schedule to its implementation in practice, through several individual or collective validation steps. Reliable planning "requires that planners and stakeholders have not misestimated, mis-specified or misunderstood the options they have chosen. This is the ultimate cognitive foundation for high reliability management" (Schulman 2012, p. 56). In this, collective discussion but also the diversity of viewpoints or "conceptual slack" (Schulman 1993) are very important.

This paper explores the socio-material dimension of organizational reliability by considering planning as a social and political activity (Clarke 1999; Gautherau and Hollnagel 2005; Schulman 2012) and the schedule as an object with cognitive, interactional and symbolic dimensions. To study the role of planning and schedules, the concept of the boundary object is applied. This alternative perspective on social interactions considers the role of objects and the profound impact such non-human actors can have on human actors (Suchman 1987; Star and Griesemer 1989).

In this sense, a boundary is not an edge but rather "a shared space, where exactly that sense of here and there are confounded" (Star 2010, pp. 602-603). Boundary objects are not static material objects, but rather "the stuff of action" (2010, p. 603) and can be abstract or concrete. They inhabit, are used in, several social worlds and thus form a common boundary between these worlds. They support coordination and cooperation between worlds by satisfying the informational needs of each of them, since they are at the same time "weakly structured in common use, and become strongly structured in individual use" (Star and Griesemer 1989, p. 393). Thanks to their interpretive flexibility, each social group can associate different meanings with the object to answer its special requirements and local needs. Yet, thanks to their common structure recognizable by different social groups, they maintain a common identity and constitute a mean of translation of knowledge, information and practices between groups: "Boundary objects are a sort of arrangement that allow different groups to work together without consensus" (Star 2010, p. 602).

The notion of boundary objects has been used in a range of ethnographic research particularly in the field of organization studies, in sociology of science and technology and in knowledge management [see Trompette and Vinck (2009) for a detailed review]. Yet, it has not been picked up by safety researchers. In addition, limited review of the literature identifies only two papers on the subject of schedules as boundary objects (Chang et al. 2013; Yakura 2002). This constitutes a significant gap in the literature on planning for organizational reliability that this article goes some way to address.

\section{Methodology}

The research approach is longitudinal and qualitative. Conducting research in strong 
collaboration with practitioners ensured a privileged and long-term access to the field. The analysis of empirical material was based on a grounded theory approach, following a continuous and cumulative process.

\subsection{Research setting and approach}

Fieldwork has been conducted since July 2013 as part of a long-term, ongoing inquiry into planning at NucCo (a pseudonym), a nuclear plant specialized in the processing of nuclear fuel. NucCo employs 5000 workers, including 2500 contractors. This very large and complex organization faces the challenge of managing and operating technologies capable of failing with catastrophic consequences. Yet, the safety goal cannot be achieved at the expense of industrial performance (and vice versa).

This plant is characterized by its technical and spatio-temporal distribution. The work is divided between two lines of production and each comprises four to five workshops (see Fig. 1). These production lines are described as "tubes" by the workers to emphasize the strong interdependencies between the workshops; the input of a workshop is the output of the previous one in the line. Thus, the nuclear plant is strongly coupled (Perrow 1999), and unexpected events in one place can have an effect on the whole line.

\section{Fig. 1}

NucCo's technical organization

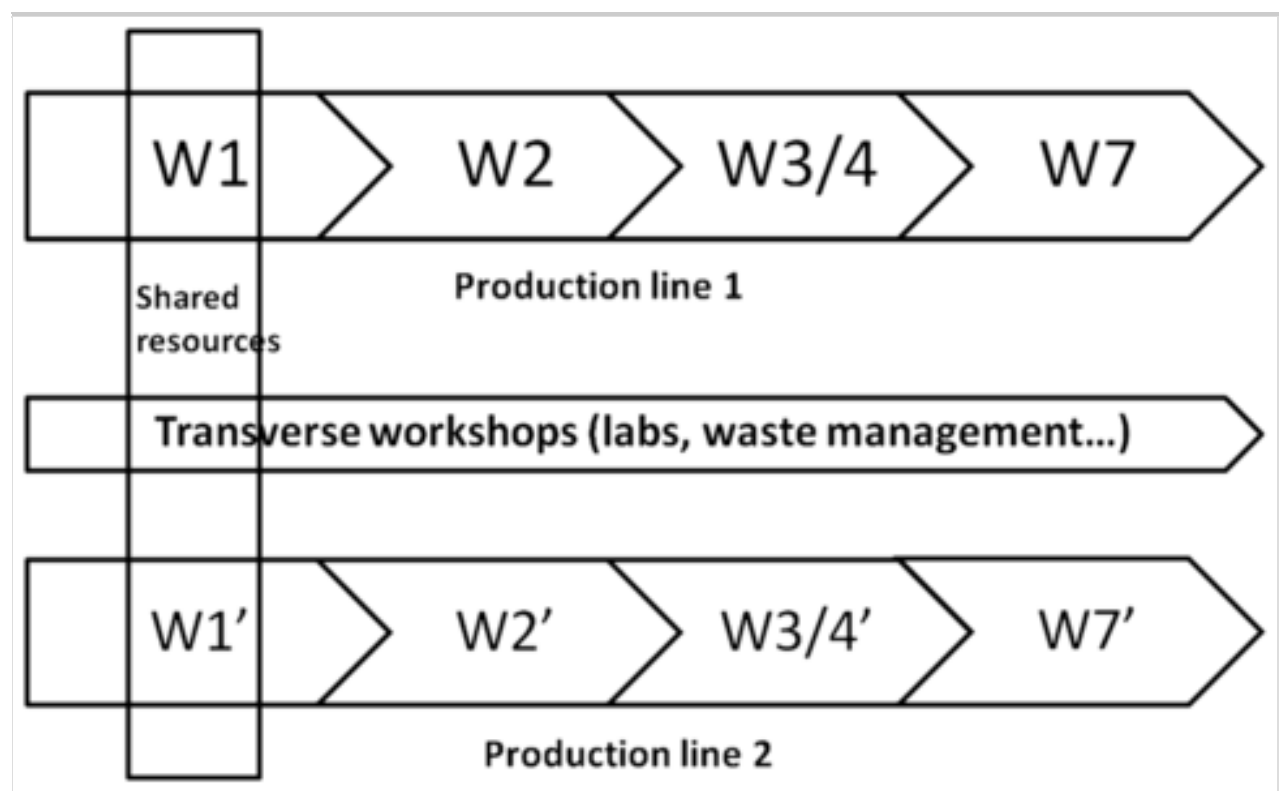

The safe functioning of the plant relies on the work of several interdependent occupational groups. The production teams, which are distributed in the different workshops, are in charge of monitoring the production process of their workshop from a remote control room, to prevent any contact with radioactive material. These teams are organized in continuous shifts composed of operators and a shift supervisor. Each workshop is supervised by a production manager. The other main occupational group is maintenance, 
which is organized by preventive and corrective maintenance supervisors. Preventive maintenance is scheduled, routine maintenance to keep equipment such as pumps running well. It is conducted on equipment where failure has significant production and/or safety implications, so running to breakdown is not appropriate. When such equipment fails unexpectedly, corrective maintenance is required to bring it back on line as quickly as possible. In the nuclear processing plant, no maintenance activities are undertaken by production personnel. Whilst most corrective operations are carried out by NucCo employees, more than $80 \%$ of the preventive maintenance is contracted. Contractors intervene on the whole plant, while NucCo maintainers are assigned to a specific workshop. The realization of the maintenance tasks is very dependent on production teams, since maintenance needs their agreement to intervene when the facilities need to be stopped. Except for corrective maintenance, all maintenance operations are planned very carefully to ensure that they are carried out safely and at the 'right time'. Production and maintenance teams are helped in this by planners who are assigned to one or two workshops, and build schedules on a weekly basis, from information gathered during planning meetings and from the maintenance software. The concrete form of a schedule is as follows: it depicts the order and duration of tasks through a Gantt diagram, but also important information about special precautions associated with the realization of a given task or incompatibilities between tasks. It also indicates who is in charge of the task and which contract is associated with it.

The plant operates $24 \mathrm{~h}$ a day, 7 days a week, except during maintenance outages (two per year and per production line), throughout which major maintenance activities are carried out: scheduled repairs, legally mandated testing of equipment, upgrades required for technical improvements.

At this site, planning has taken on increasing importance in recent years, linked to increasing production pressure from management. Improved planning is seen as a way to reduce non-value added time. Indeed, schedules are not built outside a structured framework, but respect standards fixed by the management. Rigorous planning becomes even more important with the rationalization of outages and their shorter durations.

Given these characteristics, NucCo provides fertile ground for studying planning in highrisk industries and the links between planning and organizational reliability.

\subsection{Data collection and analysis}

Building on Yakura's work (2002), fieldwork aimed to collect precise descriptive data on how schedules are used in practice. In the HRO tradition, the study addresses the "normal" (Bourrier 2002) or "normally disturbed" (Journé and Raulet-Croset 2008) functioning of the plant.

To understand how the schedules were built, discussed and exchanged, and considering the scheduling process as an organized activity, fieldwork was conducted from June 2013 
until September 2016 during 25 immersions lasting from 2 to 3 days each. In total, 57 days were spent at NucCo. This enabłed scheduling practices to be studied under a wide variety of conditions. As non-participant observers, researchers attended 63 planning meetings during both normal production and outages. During these meetings, the nature of exchanges between workers and their relationships to schedules in their material dimension were closely studied. In addition to the observation of planning meetings, 53 semi-structured interviews with workers from top management to operators were conducted including members of each occupational group (maintenance workers-both NucCo employees and contractors, planners, production supervisors and managers). During the interviews, questions were asked about their work, their constraints, their involvement in planning, their use of schedules, and what was, according to them, a good schedule (see Table 1). Interviews lasted from 90 to $150 \mathrm{~min}$. The duration of the interviews was driven by the interviewees and not the researchers, which shows the level of interest in this topic. They were all audio recorded and transcribed to be coded.

Fig. 2

Analytical process of data collection and coding
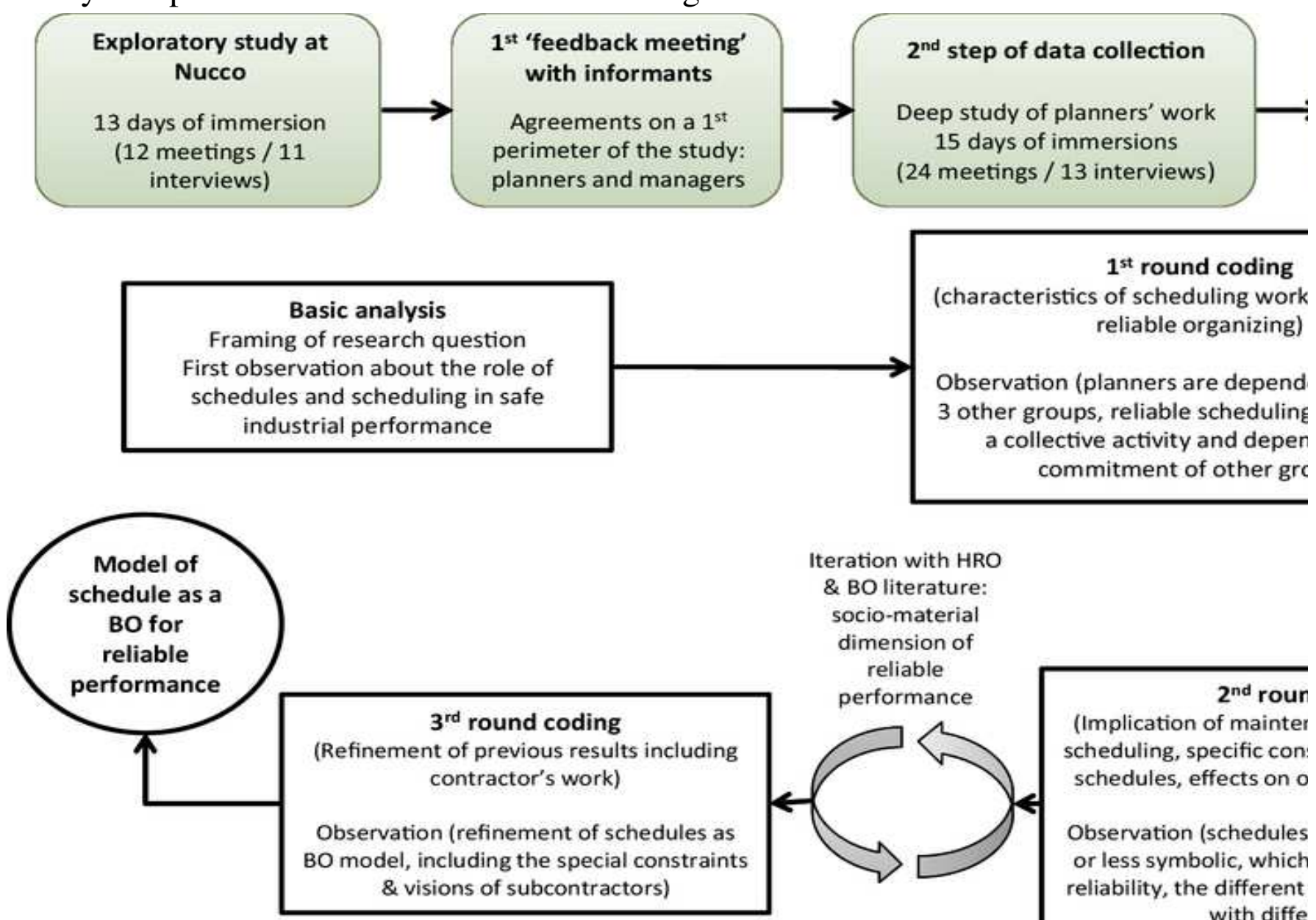

Iteration with $\mathrm{HRO}$ \& BO literature: socio-material dimension of reliable performance

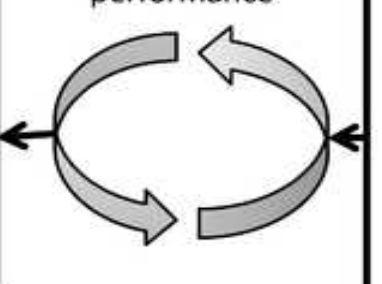

$2^{\text {nd }}$ rour (Implication of mainter scheduling, specific con: schedules, effects on o

Observation (schedules or less symbolic, which reliability, the different with diffe

\section{$4^{\text {th }}$ 'feedback meeting' with informants}

Sharing and discussing final research findings with informants $4^{\text {th }}$ step of data collection

Contractors' work

9 days of immersion

(5 meetings, 6 interviews, 2 focus-groups) $3^{\text {rd }}$ 'feedback meeting' with informants

Sharing and discussing research findings with informants

Agreements to enlarge the study to contractors 
Table 1

Data collection and analysis

\begin{tabular}{|l|l|l|l|}
\hline & Data collected & $\begin{array}{l}\text { Data } \\
\text { collection } \\
\text { period }\end{array}$ & $\begin{array}{l}\text { Data analysis and use for theory } \\
\text { development }\end{array}$ \\
\hline $\begin{array}{l}\text { Semi-structured } \\
\text { interviews }\end{array}$ & 53 & & \\
\hline $\begin{array}{l}\text { Individual and } \\
\text { recorded interviews, } \\
\text { with a duration from } \\
90 \text { to 150 min }\end{array}$ & $\begin{array}{l}\text { October } \\
\text { 2013 to } \\
\text { September } \\
2016\end{array}$ & $\begin{array}{l}\text { Data transcription and coding: } \\
\text { definition of categories and related } \\
\text { concepts to explain observed } \\
\text { phenomena (mainly articulation of } \\
\text { work activities and management of } \\
\text { unexpected events) }\end{array}$ \\
\hline
\end{tabular}




\section{Data}

Data collected

\begin{tabular}{|c|c|c|c|}
\hline Planners & 15 interviews & & \\
\hline Maintenance & 20 interviews & & \\
\hline Production & 7 interviews & & \\
\hline $\begin{array}{l}\text { Managers } \\
\text { (including outage } \\
\text { project manager) }\end{array}$ & 5 interviews & & \\
\hline Contractors & $\begin{array}{l}\text { Six individual } \\
\text { interviews } \\
\text { Two group } \\
\text { interviews with } \\
\text { ten managers of } \\
\text { contracting } \\
\text { companies }\end{array}$ & & \\
\hline Observations & & & Transcription of observation notes \\
\hline $\begin{array}{l}\text { Direct observations } \\
\text { of planning meetings }\end{array}$ & 63 meetings & \multirow{2}{*}{$\begin{array}{l}\text { January } 2014 \\
\text { to September } \\
2016\end{array}$} & \multirow{2}{*}{$\begin{array}{l}\text { Analysis of verbal communication } \\
\text { and of use of artefacts } \\
\text { Identification of contingencies and } \\
\text { disturbances of work course, and of } \\
\text { built arrangements } \\
\text { Understanding of how actors build } \\
\text { and negotiate task planning, and } \\
\text { how they discuss work content, } \\
\text { roles and responsibilities }\end{array}$} \\
\hline $\begin{array}{l}\text { Direct observations } \\
\text { of maintenance tasks }\end{array}$ & $\begin{array}{l}\text { Observation of } \\
6 \text { half-days }\end{array}$ & & \\
\hline
\end{tabular}

The qualitative research was conducted using a grounded theory approach (Corbin and Strauss 2014). Adopting this approach means beginning the study with inductive data, engaging in simultaneous data collection and analysis, adopting comparative methods and defining and refining codes and related emergent concepts throughout the research process. As shown in Fig. 2, the analytical process was iterative and cumulative, and built around four main steps of data collection and four associated rounds of coding. The first step was an exploratory study, aiming at defining with the informants the research question and the perimeter of analysis. 12 meetings were observed and 11 interviews undertaken. A basic analysis was conducted at this point aimed at identifying the main issues and comparing how they were presented according to the informants and their function. This enabled the first research question to be framed around how planning could support (or not) safe industrial performance. Each step concluded with a feedback meeting with a representative sample of informants during which main observations were shared and discussed. This step concluded with an agreement on the research question and the perimeter of the research, in that case the work of planners. The second step thus concerned a deep study of planners' work through the observation of 24 meetings and 13 additional interviews. Our sample was totally representative, since all planners of NucCo were interviewed and observed when leading planning meetings. Apart from planners, these meetings also gave the opportunity to make first contacts with people from 
maintenance and production. All the data collected were analyzed through the first round coding, identifying the main categories and the subcategories through permanent comparisons of data with data, data with codes and codes with codes. This enabled to identify the roles of planners, schedules and scheduling in reliable performance .

Table 2

Initial coding on planners' work

Main categories

Definition of
occupational territory

Schedules and scheduling roles

\section{Subcategories}

\section{Definition of my role}

Definition of other

occupation's roles

Multiple belongings

Managing contradiction

Who is responsible for

planning?

Credibility/legitimacy of

planners

«post-it »

List

Reporting/accountability

Prescription

Exploration

Opportunity to meet and

discuss

A commitment (symbolic?)

from production

Proof/agreement formalization

Coordination

\section{Realism}

A good schedule?

Collective nature

Shared construction

Granularity

\section{Associated quotes (for confidentiality reasons, quotes are not displayed)}

Conditions affecting roles and uses of schedules

Planners' work

\section{Conflict with OTD}

Control

Material form of schedules

Commitment of actors

Heterogeneity of scheduling practices

Articulation/interactional practices

Skills and knowledge

The main observation from this stage of the work was that a deep understanding of the role of scheduling required enlarging the study by looking at the interdependent occupational groups, mainly maintenance and production, due to their strong impact on planners' work. The second feedback meeting concluded with NucCo authorizing researchers to conduct a third phase of data collection and analysis with production and 
maintenance actors. During the third step of data collection and coding, maintenance and production work was studied through the observation of 22 meetings and 23 interviews. The second round of focused coding enabled planners' data to be compared with new data and to refine our codes and categories (see Table 2). At this point, researchers were able to identify emergent concepts and to begin theory building. The last phase focused on the work of contractors ensuring that the model takes this issue into account.

A reflexive approach was developed to ensure the relevance of post-observation analysis and to enrich it. Four feedback meetings were organized with field actors to share and discuss findings. Intermediary and final research findings were presented to a group that was representative of the original interviewees and then debated internally until consensus was reached between researchers and interviewees. No serious points of disagreement were identified, but this process allowed the interpretations of practices and relationships within and between the various social worlds to be refined.

\section{Empirical results}

Following Star and Griesemer (1989), an ecological approach has been adopted that does not favour the point of view of one actor over another, but aims to understand interactions between worlds. To show the diversity of actors' practices and perspectives on planning, the perspective of each group is presented using one actor representative of a given occupational group to explore the role and goal of planning, their relationship to planning, their vision of time, the resources they use to plan and carry out their work and the constraints they have in relation to planning. Through the prism of schedules and scheduling, the discussion highlights how the occupational groups negotiate to organize and manage their interrelated activities, both in expected and unexpected situations. The results are summarized in Table 3.

AQ2

\section{Table 3}

Five social worlds' interactions with schedules

\section{Maintenance supervisors}

Overall objective of the schedule

Defining the right time to perform work

\section{Operators}

Getting maintenance work done with minimum disruption to production

\section{Preventive}

Temporal focus
Middle-term time horizon (1-5 weeks)
Very shortterm time horizon linked Negotiated time to OTD

Negotiated time

\section{Planners}

Supporting coordination between maintenance and production

\section{Subcontractors Managers}

Showing all

Supporting coordination of resources between workshops

Very-short term time horizon to deal with emergencies tasks, so wo can be effectively supervised $t$ reduce downtime

Productive time Added-valu time 


\section{Maintenance}

supervisors

Corrective

Very short term ('as

soon as

possible')

Active

presence in

Involvement

in planning

work

planning

meetings

Planning as

an

"additional

effort" indicator

Perceived

disengagement

and lack of

commitment

Production out

of touch with

planning
Middle to long

term to plan

human

resources

The most directly

involved in

scheduling

activity

In charge of

building and

sharing schedules
Largely

uninvolved, but

would like to be

more involved

in formal

scheduling processes
'Real time' (including invisible times)

Not involve directly, but very strong influence or scheduling standards
Helpful in

Schedules as daily

alerts,

reminders,

checklists,

proofs of

Role of

schedules

and

scheduling formal

agreements

Anticipation

Increased

sensitivity to

operations

Management

of the

unexpected negotiations

with

maintenance,

but not seen as

binding on

operations

Helpful in

managing the

unexpected,

building

scenarios and

developing a

longer-term

view
Making impact and

interdependencies

visible and

manageable for

maintenance and

production

Scheduling is as

important as

schedules due to

relationship

development
A way in which they are

excluded from

overall decision

making

A lost

opportunity for

resource

smoothing

Commercial

risk linked to

level of detail

requested
Planning as

strategic for industrial

performance

Supporting

production

performance

Reducing

maintenancs

times and

chasing

unproductiv

time
Production's lack of

Obstacles to reliable planning commitment

Incomplete

vision of

contracted

maintenance

work
Crisis working mode leading

to fewer

maintenance

activities

being

authorized.

Conflict with

management

tools (e.g.

OTD

indicator)
Lack of

interactional

skills,

organizational

knowledge and

sensitivity to

occupational and

individual

specificities

Lack of

commitment of

other groups

\section{Nucco's}

organizational

complexity $\rightarrow$

multiplicity of

interfaces and

contact persons

Preference for

segmentation of

scheduling

work, rather

than a global

view

Wide variety of

scheduling

practices

Schedules that

are rigid and

too detailed

(issues to deal

with the

unexpected)

Legitimizing

and

Symbolic

dimension

of

scheduling recognizing

maintenance

workload and

value

Increased
Planners as

"marginal

people" who

inhabit several

social worlds

Scheduling work

is largely
Conserving

autonomy from

low granularity

of schedules

Time as an

object of

negotiation
Heterogenei

of working :

scheduling

practices

Lack of

planning

culture
Managemen
control via
standardizat
and
rationalizati
of schedulin
practices 
Maintenance

supervisors

control from

management

and reduced

leeway in

case of very

detailed

schedules invisible and unrecognized Problems of legitimacy and authority
Commercial relationships as an impediment to make some "invisible" times explicit

\subsection{The preventive and corrective maintenance: Michael's and John's perspective}

An important participant in the planning process is the preventive and corrective maintenance department. Michael and John are in charge, respectively, of the preventive and corrective maintenance of $\mathrm{W} 1$ and $\mathrm{W} 1$ '. Maintenance is organized in planning meetings that should gather together, besides themselves, the planner and a member of production. During these meetings, they stipulate maintenance tasks that need to be carried out, the required resources and the proposed intervention dates. Defining the 'right time' to intervene is difficult since most maintenance operations require a production shutdown. It also varies depending on the type of maintenance carried out. Michael is mostly focusing on a middle-term time horizon (1-5 weeks). To him, the 'right time' is a compromise between production constraints and regulatory and safety requirements that he represents. John, the corrective maintenance supervisor, works in the short term. To him, the 'right time' is 'as soon as possible', depending on the severity of the failure and the availability of resources.

Defining the 'right time' constitutes a condition of reliable planning. The schedule will only display an intervention date and duration, but to support the reliable carrying out and articulation of corresponding activities, it must integrate (even implicitly) 'invisible time'. This includes the time to prepare intervention files, work permits and equipment, the time for production supervisors to obtain agreement on intervention time slots or for contractors to respond regarding resource availability. Invisible time corresponds to "invisible" actors who have a pivotal role in performing the planned activities. Reliable planning is thus necessarily a collective construct, which requires the cooperation of those invisible actors to anticipate and detect problems, particularly those related to incompatibilities.

To Michael and John, planning and schedules can constitute a real resource for maintenance work. Planning, as a collective process, supports coordination: a planning meeting offers space to discuss and "be in tune". It involves providing and sharing explicit information on tasks and constraints which thus enables more satisfactory agreement. It 
helps to identify resources incompatibilities and enables a global vision of interdependencies: "With planning, I can see when I'm going to penalize other departments".

For Michael and John, planning is a way to "trace" and "make official" agreements with production teams. Given its material nature, the schedule becomes a "commitment" from production teams: "At least, since we agree on a schedule, it's recorded. (...) When we said 'we'll carry out this operation a given day', if it's just verbal with production teams, they can say 'no, we didn't say that!' (...) They always find lots of excuses for not doing so. Now I can say 'listen, you were there because it's on the schedule, it's recorded that we must do it today'. The schedule is the evidence that everyone agreed on that day."

With these diverse uses, planning plays a key role in anticipating and making workers more sensitive to the operations and their risks. But more surprisingly, it also helps in managing the unexpected and increasing mindfulness: it helps to "reconstitute the chronological order of intervention, determine the "right' time" through the discussion of hidden times that may induce errors or create problems for action. Schedules are used as an alert, reminder, checklist, proof of formal agreement, and shared and global representation of impacts and constraints related to operation. Through these functional and symbolic uses, the schedule becomes a boundary object and supports planning for reliability.

Despite the benefits of planning, it does not have top priority for maintenance actors. To Michael and John, planning is still an "additional effort": "Today, the schedule is a tool, but an additional tool, we need to make an effort! (...) It's something extra, so when we do not have time uh... it's not the number one priority!" The major priority issue concerns the relationships with the production teams and their lack of firm commitment to planning which includes non-attendance to planning meetings: "The operator is not there... again! There is an emergency and he doesn't care about planning!".

Even when schedules have been agreed, very often, time slots are canceled, sometimes at the last moment, despite all the necessary preparation that has been made. The agreed 'right time' can always evolve, depending on production concerns: "Planning we did on Monday, sometimes, on Friday, even on Tuesday or Wednesday, it's no longer good because they [production department] changed". Not to mention their costs, these lastminute cancellations have symbolic implications. Maintenance supervisors feel that their work is less valuable or recognized than production: "Maintenance isn't the priority, the priority goes to production".

Apart from production, the other key constraint is contract worker resources which are shared across the whole plant. Given Michael and John's more limited responsibilities, they do not have a complete vision of the work carried out by contractors and the way they manage priorities between planned or urgent maintenance and between the different workshops. This can lead to frequent adjournment or cancellation of operations prepared 
months before, because contractors are required elsewhere: "It's the contractor who says 'I have a problem for this week' because we plan without taking into account his workload (...). Sometimes actually they are in lack of staff so we planned a date and then they call 'there I can't, I have too much emergency work, is it possible to move it back?'” Part of the problem is due to the fact that contractors are not invited to attend planning meetings, so that planning is not totally collective.

The way the schedule is used and controlled by management also highlights the symbolic dimension of planning. When management imposes a requirement for very detailed planning of maintenance activities, Michael and John consider that planning can reduce their level of discretion on how and when work is conducted.

"Sometimes, honestly, they can tickle for petty issues! 'Why is it not done?' But it does not matter we have all the time to do it! 'Oh but it had to be done today!"”

"A good schedule is to find the essential information about 'high impact' tasks, without being polluted by things that... not that we don't care about but that we can do whenever we want, I mean it doesn't matter."

To them, management, through schedules, encroaches on their occupational jurisdiction, thus calling their professional expertise into question. One particular management tool is denounced by maintenance: the on-time delivery indicator (OTD). This measure of plant performance only focuses on production volume, without regard for other criteria such as the number of cancelled maintenance operations, or the regulatory inspection obligations: "OTD takes precedence over everything else. You can plan anything you want, but if $2.2 \mathrm{~g}$ are lacking, it's production that prevails!".

OTD requirements severely limit the negotiating capacities of maintenance supervisors with other social worlds, whether they are production supervisors or contractors. Ultimate power and authority is invested by the organization in visible measures of short-term production embodied in OTD. Maintenance activity is mostly carried out with a much lower level of attention from other social worlds.

\subsection{The nuclear operator: Dan's perspective}

Another very important actor in the scheduling work is production. Their relationship to planning is especially interesting since other occupational groups, including management, often complain about their lack of concern and commitment to this activity and its outputs: "Ask yourself this: have you ever seen in a control room a schedule displayed somewhere? No! What I'm saying is that it's clearly not a steering tool for operators." (Manager). 
constraints within the plant. Dan is the production supervisor for the workshop W1. He supervises three shifts of seven production operators. Their main goal is to fulfill production requirements, in terms of tons of nuclear material to treat. The indicator that mostly drives their activity is OTD. In theory, OTD is supposed to be calculated per month, but in practice top management has placed a spotlight on OTD on a daily basis. Production personnel are thus focused on a very short-term time horizon. To Dan, maximizing production including by reducing any production stoppage is crucial. But OTD is difficult to achieve, given the many problems to deal with, as he explains to us: "When we look at the OTD they gave us, it's basically the plant at full capacity, so I have absolutely no leeway! [...] Hardly a day passes without two or three annoying events, so we are fully focused on the job all the time, all the time, all the time. We are overloaded in that job! [...] There are many unexpected events, many breakdowns, and many slowdowns to be dealt with, so it's extremely time-consuming... and we cannot simply say: the pump failed, I'll deal with this tomorrow, no! Because the pump stopped the production workshop and we do have to report to the minute information."

Given this situation, Dan routinely works in crisis mode. The time frame in which he thinks impacts his decisions. If he thinks in the short term, he is tempted to authorize less preventive maintenance operations to maximize production. But a longer-term view shows the risk of such practices that can lead to more breakdowns and ultimately more stoppage time. An important part of his job is making compromises between multiple requirements, i.e. production, safety and keeping the installations in proper conditions for use. This requires real-time data regarding production rate, planned maintenance tasks and available resources, which engage many social worlds with different priorities and lead to many negotiations. He is in close contact with maintenance teams, and yet interacts differently with preventive and corrective maintainers. On the one hand, operators are dependent on corrective teams since they need them to act quickly to address technical problems and minimize production stoppage. On the other hand, production is responsible for giving corrective and preventive maintenance teams the authorization to intervene. Since Dan has authority over W1 installations and controls access to them, he plays a central role in organizing maintenance activities.

The schedules help in those daily negotiations, but they do not seem to be perceived and used by production as a steering tool, and so production often seems out of touch with planning. However, when they are facing a crisis, for example when two workshops each have a breakdown with production and/or safety implications, that requires the same scarce resources, production people, together with maintenance, go back to schedules. To prevent an unexpected event from becoming a major problem, schedules are discussed, annotated, colored by the professionals which helps them to build scenarios that support anticipation and collective decision-making. Even if they are not always conscious of it, schedules help Dan and his colleagues to take into account interdependencies (e.g. best allocation of resources) and develop a longer-term view. 


\subsection{The planner: Vivian's perspective}

Vivian has been a planner for 3 years at NucCo. Before being a planner, she worked for production and communication departments in roles unrelated to planning. This gives her precise knowledge and experience of the functioning of the plant that are very useful for scheduling work.

Planners are the professionals who are most directly involved in the scheduling activity. Technically, they are the only ones who have the right to use the digital planning tool. During scheduling meetings, planners have their hands on the keyboard and mouse and they take notes of information given by maintenance and production. Finally, it is they who distribute the approved schedules.

Vivian is very committed to her planning mission. She is always focused on building schedules that are as useful as possible for production and maintenance workers, i.e. schedules showing key information about production impact and interdependencies between operations, workshops or occupational groups. On this topic, she explains: "If I' $m$ a production worker, I need to know when the maintenance workers will begin their work: 'By the way I forget, they kick off at $8 \mathrm{am}$ or $5 \mathrm{am}$ ? Oh, I have the schedule!' What we want is that each group remembers that operation. This is information that we want to put as an 'aide-mémoire', in evidence for people using the schedule."

To her, scheduling goes far beyond technical mastery: it requires specific skills and sensitivity both to occupational and individual specificities. Very conscious of the symbolic and political dimensions of scheduling, she explains: "through the schedule, everyone shows up and points out its problems". Box 1 highlights scheduling practices and skills implemented in order to build reliable schedules. 
Box 1: the making of a specific schedule

The scene takes place in Vivian's office. Maintenance workers are about to arrive for her to build with them, at their request, a specific schedule related to a complex activity. Before this meeting, she explains to us how she will go about building this schedule.

"You see, the goal is to ask questions to reach a meaningful common vision of the activity. I arrive with a blank schedule: it is created, there is a title, but I don't seek the information in advance. I don't want to write anything in the tool, because I don't want to orientate the schedule. When they arrive, I say to them: 'tell me your story!' Like this, nothing is left out. I don't ask them for work orders, I don't ask them the duration of the tasks, etc. I ask them for the story! Linking tasks to tasks, it's just parasitic work that pollutes life, and you don't get the proper information. People come from different functions, you see, and each time I ask them: 'You, in your function, what do you need?' 'Well, I need 11 of acid.' 'Ok, but caution! Your acid litre, where does it come from? What precautions should be taken?', etc. The question is: how can I make them clarify things so that nothing is forgotten. Then they leave, I translate all this into the schedule, and I send it to them. Even if they don't open the PDF file, I know that thanks to the meeting, everybody has the story. It's not always simple because this afternoon for example, production won't be there. It's maintenance that is in charge of the activity. They want to be proactive and they don't really want production to be here, at least for the first one. It bothers me because if the operator is not here, one can perfectly say, at least I say it (laughs), that the schedule won't be robust. But they [maintenance], their logic is 
To Vivian, the scheduling process is as important as the object 'schedule' itself. Indeed, she sometimes describes schedules as "candy"- a pretext to gather people. As shown in the boxed example, Vivian has developed interactional practices (making people tell their story and reveal invisible times and hidden requirements) and organizational knowledge to better manage interdependencies and maximize the reliability of the schedules. Not all planners have these abilities, mostly because some of them (due to their background) have no knowledge related to technical functioning and constraints.

Planners are very dependent on the other occupational groups, especially maintenance and production, to get information; the capacity of the schedule to support cooperation depends on the cooperation of maintenance and production during the scheduling process, but also on the commitment of planners to collecting reliable information from diverse sources. Vivian considers that it is her job to get the data necessary to build a reliable schedule, but not all planners share this perception. During a meeting, another planner explicates: "I always say, if it's in the schedule, it's because they told me. If it's not, it's not my fault! It's called transfer of responsibility. We just transcribe the information."

Planners can be defined as "marginal" people since they inhabit or have "membership in more than one social world" (Star and Griesemer 1989). First, they officially report to the planning department. But since they are assigned to specific workshops and physically have their office in the workshop, they often feel as if they belong to one particular workshop. For example, they are asked during outage project meetings to represent other occupational groups, such as maintenance: "We're often treated as representatives of other groups during the outage project, something we are not! Many people are invited, who don't come, and the planner is supposed to know everything and to answer for them. We get the impression that our boss is the project manager or maintenance. Make no mistake! We begin to be the planner of THAT workshop!"

With regard to coordination, this marginal position can be an advantage since they have access to information from multiple social worlds. Yet, these multiple belongings can also make it hard for planners to find their place in the organization from a functional and symbolic point of view. Since they have absolutely no authority over the tasks they are planning, their work often stays invisible and thus unrecognized, formally or informally, by other occupational groups. The only way for them to gain legitimacy is, as Vivian has done, to build reliable and meaningful schedules, which become valued as a real help in the conduct of work by maintenance and production.

\subsection{The contractor: David's perspective}

Since NucCo contracts out much maintenance activity (around $80 \%$ of preventive maintenance), contractors are very close to internal maintenance supervisors and share many viewpoints and concerns towards planning and scheduling. 
repairing major safety equipment. He has worked at the plant for many years, so has a very deep knowledge of it. Unlike NucCo's employees, David's teams are not assigned to one specific workshop. They work in nearly all areas of the plant, depending on need, giving them a more global and transverse vision of the plant than most of NucCo's employees. Their work requires NucCo to agree on the workload division between different workshops and yet, as David points out in interview, it is sometimes hard to identify the appropriate NucCo decision-maker as a result of the multiplicity of commercial and technical contacts and interfaces. This organizational complexity makes it hard to define priorities between requests of the different stakeholders which, according to David, do not always communicate amongst themselves.

This problem is particularly significant when the plant is running (as opposed to during an outage), since weekly planning is undertaken independently in each workshop. To David, not being invited to planning meetings reinforces this problem. To make matters even more difficult, the planning practices differ considerably from one workshop to another. There are no standardized procedures, or when there are, they are not applied the same way across the different workshops. David explains: "there are workshops where we have the information directly from production and others where maintenance supervisors are real driving forces and we get information directly from them. And in some workshops, even if we plan something, the operators always call it into question."

Whether the plant is running or not, contractors are very concerned with the issue of unexpected events: a work permit not ready at the scheduled time, a scarce resource like radioprotection unavailable, an emergency that requires resources to be reallocated elsewhere, an operator who refuses to hand over the installation for maintenance because OTD is not reached: "We are at the disposal of NucCo's production. They are always the priority." To be able to flexibly (re)organize their activities in the face of unforeseen and unforeseeable events, David's teams need to conserve a degree of autonomy. According to David, this issue is clearly linked to planning logic and to the degree of heavy handed conservatism of schedules: "To build a good schedule [...] the definition of tasks "with impact' and tasks 'without impact' is very, very important. If everything is important, with impact, it doesn't work, it's not possible, we have to stop kidding! Some people, not to be annoyed, say: 'I will put everything with impact so it will be in the schedule and so it's easier to monitor'. This isn't planning!"

In this complex work context, with a lot of co-activity, planning should, for David, focus on activities that can truly impact the work of others. Adaptive management requires building schedules that display only tasks with production impact. A schedule that attempts to show every task, including the more insignificant, is more constraining for action (especially in the face of the unexpected) than enabling and does not support global vision of activities. In this, they share with maintenance the vision of a reliable schedule.

Despite the difficulties mentioned above, scheduling is seen as very important and is clearly supported by the contractors. The criticisms do not concern scheduling itself, as a 
process, but the client organization. In a slightly provocative and ironic way, David asserts: "Fortunately we organize to cope with the client's disorganization." Globally, they would like to be more involved in planning (e.g. participating in meetings, receiving written schedules or even having access to the planning tool) and in discussions regarding the upgrading of the planning process.

While they share many of maintenance's perspectives, contractors have also specific planning issues. As David explains, planning is inseparable from human resources management. They need a reliable schedule to determine the resources needed and to smooth those requirements. That also explains why the issue of tasks 'with' or 'without impact' is crucial to them. Having some unplanned tasks in their work scope enables them to retain some autonomy and to have some slack, indispensable to managing both resourcing and unexpected events. Their particular relationship to planning is linked to their dual relationship to time. Contractually, they are expected to deal with emergencies and so must be focused and reactive on a very short-term time horizon. But as a manager, David needs visibility on workload in the long term to plan human resource requirements. Time clearly has a political dimension, since it is an object of negotiation. To contractors, revealing to their client some details regarding planned activities, such as the precise duration of tasks (including preparation time) or precise types of resources needed, is undesirable since it can constitute competitive benchmarking data. This position clearly contradicts the desire of NucCo's actors (especially the managers) to control work through very detailed schedules, which even include invisible work such as margins. The commercial relationships are such that making these 'invisible times' explicit is clearly impossible for contractors.

\subsection{The manager: Tomas' perspective}

The final group that has a significant interaction with the schedule is management. Managers have a direct influence on the parameters that define the perceived reliability of planning processes, the tools available for planning and, at times, on the details of specific schedules. They are also responsible for setting up the OTD performance indicators, which can be in conflict with maintenance schedules.

Critically for managers, NucCo is currently engaged in a strategic review aimed at improving production performance through more effective control of downtime. Besides the implementation and focus on the OTD indicator, the review includes rationalizing and improving planning processes, but there seems to be little understanding of the conflict experienced at a working level between these two forms of bureaucratic control. According to Tomas, the outage project manager, one key area for improvement concerns the planning of maintenance activities: "A central pillar of our strategy is called planned maintenance. All the deliberation concerns planning of the tasks and this year will be a pivotal year since planning is at the heart of our policy. Planning means of course stakeholders but also tools". 
Tomas, as with most managers, is conscious of the lack of reliability of planning. To him, planning problems are rooted in the organization and not strictly linked to the schedules: "It's on the organizational side that we have problems, given the complexity of the whole organization. The planning culture is not rooted at all today. I've never seen an operator monitoring his weekly schedule. It must become cultural, for the first thing to be: 'what is my schedule? What did I plan and with what do I monitor?'.” To Tomas, less than optimum use of time is above all an organizational and managerial issue that he often links, as do others, to the lack of "planning culture", by which he means a lack of focus at a working level on getting maintenance work done in accordance with appropriate schedules.

To be more reliable in Tomas' view, planning must reach three main objectives and conditions. First, planning must support production performance. This is directly linked to the control of time, and chasing unproductive time: "One challenge regarding planning, and efficient planning, is to seek to reduce non-value added time. And again, this doesn't concern the tool, but mainly the organization and the culture." To do so, planning must serve the OTD objective. The exchanges below between Tomas and other managers during one of the research results workshops show that most managers clearly agree on that vision:

- "I think the planning process should be built in order to respond to the OTD obligation.

- I agree. Today, if you don't do that, you're wrong. I mean if you begin to say to people; 'I give you margins', it's screwed before you start!"

Secondly, Tomas advocates that planning practices should be standardized. Having a transverse view across all the workshops and their interdependencies, Tomas is conscious of the fact that the heterogeneity of working and planning practices affect planning reliability: "planning is made through Excel files, and not in the same way in the different workshops. In our search for standardization, how can the tool help the operator?"

The standardization of processes is a work in progress through efforts to define rules and initiate a cultural shift, primarily about the impact of specific tasks on other parts of the plant. Lots of discussions are centred on defining planning methods and standards. "The important question is: what are the good rules that need to be relearned when we want to make good schedules? I think today, people have often been made to feel that planning is something simple: we take a schedule and we just put tasks into it one after the other. It's not just that! This is just the first step. The second step, amongst the good practices, is to relearn that when we stop a plant, it's several workshops that stop and people will work on several workshops at the same time. So we can't just say: 'I work only in my bubble, in my workshop', without taking into account the impacts that their own work can have on other activities and people. I think we have still a long way to go in this process before 
people understand that decisions they make at their own level have impact on the whole plant. This is culture they still need to acquire."

Behind this official goal, standardization also facilitates managerial control of operational activities. This leads to Tomas' third role of planning, i.e. effective steering of activities by best allocation and management of scarce resources, and best management of interdependencies at the local and global level through the building of a transverse vision. The desire to standardize is linked to the fact that managers are both physically and functionally distant from work as done. They have the impression that they have little and certainly insufficient control over information transfer and that they often fail to receive important information: "Managers! We're not in the position anymore of re-dissemination of the message, so there is misinformation close to the field." Paradoxically, Tomas is not only concerned about bottom-up communication, but also considers top-down information flow. As a manager, he wants to be sure that his decisions are followed by operators. Managers see in planning and scheduling a good and effective means of obtaining and controlling more and better quality information.

\section{The socio-material dimension of reliability}

The schedule is the artefact that connects the various occupational groups regarding plans for maintenance work, but there are both commonalities and differences in the way the schedule is used, in the definition of what is a "good" schedule, in what must/can be made explicit or remain hidden, in its role in day to day activities and in organizational reliability. Far from being a problem, these various perspectives are a condition for the schedule to form a boundary object (Star and Greisemer 1989).

\subsection{Schedule as boundary object}

The reliable operation of the plant is the goal of all actors interviewed and each group has a role to play in achieving that outcome. Yet, given the distribution of work, the management of interfaces is a challenge for reliability. When different social worlds with different meanings of 'good' work and reliability interweave, cooperation involves reconciling these meanings, which requires effort from everyone. A major problem in managing interfaces is ensuring the integrity of information in the face of such a diversity of actors and meanings, while maintaining requisite variety necessary for mindful (or high reliability) organizing (Weick and Sutcliffe 2015). In the face of this challenge, both the object that is the schedule and the process of development of the schedule have value in achieving reliable performance. The schedule is reliable if the process is.

As a boundary object, the schedule acts as a flexible object that transcends professional boundaries in a way that allows members of different social worlds to discuss maintenance tasks that are critical for the ongoing reliability of the plant. More precisely, it plays two decisive functions vis-à-vis reliability: (1) the management of interfaces in enabling crossboundary coordination; and (2) mindful organizing through sustaining a diversity of point 
of views.

- Schedules support display and representation practices, which make the work of one particular occupational group (e.g. maintenance) visible to others and make more explicit the associated expectations regarding involvement from others (for example, when schedules indicate that a task is important for safety, production actors know that they are expected to undertake a risk analysis before maintenance intervenes). These practices ensure that everyone sees the same level of information on the tasks, the difficulties associated with them, and any incompatibilities between tasks. Schedules thus shed light on the complex set of interdependent tasks and associated responsibilities and, by making expectations more explicit, help in managing complexity and priorities. In addition, the process of development sustains both anticipation and resilience. The process of building schedules (mainly through planning meetings) compels the different actors to discuss and build common scenarios on both normal and the potentially disrupted course of planned events, and to develop collective solutions. This keeps them preoccupied with failures and sensitive to operations, two principles fundamental to high reliability organizing (Weick and Sutcliffe 2015). Thanks to this, actors are collectively more able to cope with the unexpected events when they occur.

- As boundary objects, schedules enable the building of a common identity, a global vision of expected work and finally cooperation, while maintaining the diversity of viewpoints and interpretations promoted by HRO research (Weick and Sutcliffe 2015). They preserve "conceptual slack" (Schulman 1993) and prevent the search for similarity and neglect of differences, which can become potential sources of disruptive surprises and danger (Weick and Sutcliffe 2015). In this case, the interpretive flexibility and the fact that it makes cooperation possible without consensus constitute key properties of schedules as boundary objects for high reliability. As a collective process, planning constitutes an occasion for confrontation of points of views and argumentation: it maintains a "spirit of contradiction", which is essential for adaptability to change (Weick and Sutcliffe 2015).

Managing the relationship between production and maintenance when it comes to the process of schedule development is a key part of the role of the planners. This entails reconciling diverse views of activities and associated times in the form of a 'good enough' common view as depicted by the schedule, which allows all parties to move forward. Some actively seek out information and invite various actors to tell their stories, thus playing a key role in generating rich information that is taken into account when the schedule is prepared. They contribute, through planning, to the selection of key information from each work group and thus to the alertness of maintenance and production workers. As seen with Vivian, they consider scheduling to be complex work that seeks to help people to note and remember important activities, their length, and the scarce resources needed or associated constraints, but which also coordinates and maintains 
heedful interactions (Weick and Roberts 1993). Planners, when they can be considered as 'reliable professionals', are essential to reliable planning (and then reliable performance) since they avoid simplifications and thus reduce errors of underestimation or overconfidence (Schulman 2012). This aspect of the planner's role is not widely understood and the data show a wide variation in the ways in which their tasks are addressed. This leads us to question broader organizational and professional conditions that prevent schedules from being a boundary object and thus a support for reliability.

\subsection{The search for autonomy and control}

The study reveals some occupational and organizational factors on which the possibility for the schedule to act as a boundary object and thus to support reliable performance depend. Two major factors are highlighted: (1) the level of standardization imposed by management; and (2) how professionals (in this case mainly maintainers and planners) understand their roles and the skills they have developed. The impacts of these factors on scheduling practices and on the concrete form of schedules are discussed below showing that the schedules, when they cannot act as boundary objects, provide less support for high reliability organizing.

As Star and Griesemer stated, "a social world ... 'stakes out' territory" (1989, p. 411) and uses objects, in this case schedules, to do so. If boundary objects enhance cooperation between different social worlds, Bechky (2003) has shown their role in shaping and representing occupational jurisdictions. As symbolic artefacts, they are used by actors to gain legitimacy or authority over some tasks, to preserve autonomy or to (re)balance power relationships. This case concerns mainly relationships between production and maintenance, but these relationships are clearly affected by planners and managers. Analyzing planning and schedules shows that actors manipulate schedules more or less consciously to gain autonomy or control through the development of practices regarding the granularity of tasks shown. These practices impact on the role of schedules in anticipation and coordination. A good schedule is a subtle balance between what should be brought to light and what should remain hidden from view, which differs depending on the occupational group.

\subsubsection{Risks induced by tensions between standardization and autonomy}

Showing specific tasks on the schedule makes invisible work visible to all, but this has advantages and disadvantages. To maintenance actors and contractors, the primary benefit of showing many tasks is symbolic - to demonstrate to other groups how busy they are and, in particular, to emphasize their value in ensuring ongoing operations. The materiality of the schedule thus enables maintenance to make its work formally recognized, and more strategically to negotiate additional resources with management. But maintenance actors are also conscious of the potential for increased managerial control. As Star (2002) puts it, "leave the work tacit, and it fades into the wallpaper [...]. Make it explicit, and it will become a target for surveillance" (p. 120). 
At the nuclear plant, this is directly linked to management's increasing interest in planning to improve production performance. In this still bureaucratic organization, under increased production pressures, most managers see planning and schedules as a way to increase their control, to track more precisely the gap between what is planned and what is actually done and so to reduce non-value added time. This is seen in attempts to control three key factors-temporality, autonomy and the process by which schedules are generated. Schedules, perceived as a strict description of what was to be done, when and by whom, become a "locus for accountability" (Yakura 2002, p. 966). Managers defend more and more a decontextualized representation of time and force the development of standardized practices.

The schedule, in its materiality, shows work carried out in a very ordered and structured way. But, reality is much more chaotic than the envisioned order, certainty and permanence (Bucciarelli 1988) represented through schedules, as a result of unforeseen problems that only become apparent when the work is underway. The end of the story in particular often does not play out in practice in accordance with the bars on the chart. Given that work is not always completed in accordance with such jointly constructed plans, management is seeking to increase the level of standardization around the time taken to conduct various tasks in an effort to ensure that work is completed more quickly. This, in turn, requires access to more information from maintenance actors (both in-house and contractors) regarding the details that sit behind each bar on the chart.

Yet, most maintainers perceive this request for more detailed description of tasks as an infringement on their occupational territory. In response, they develop practices which aim at leaving some technical details unarticulated. For example, evidence shows that maintenance sometimes 'spread' tasks when negotiating with other groups about the duration of individual tasks on the schedule by adding more time than is strictly necessary to provide leeway in the event of difficulties, or "select tasks to make visible only the one that will please management". Adding this type of contingency or margin is frowned upon by management who state explicitly, "The message that needs to be sent, which is essential, and that I have been saying is: 'when you plan operations, do not put margins!' ... If everybody puts margins, what happens? ... You foster chaos and confusion. That's why I always say: 'Do not put margins!'." (Outage manager) This issue again reveals the tensions between control and autonomy and how this practically impacts the form of schedules.

Standardization thus introduces significant risks:

1. overly detailed and standardized schedules make activities unnecessarily rigid and inflexible: requisite variety and adaptability are reduced, and professionals become less sensitive to operations; 
supports increased management control and develop in turn "dissimulation" practices to prevent this control and the reduction of autonomy.

This is clearly a problem since the reliability of planning and schedules depends on the integrity, and not on the completeness, of information transferred by these groups. In this case, the schedule potential becomes an object of negotiation over power relationships, rather than reliable performance. As highlighted by Oswick and Robertson (2009), in some conditions boundary objects 'can equally be thought of as creating barricades and mazes, protecting and/or privileging different interest groups' frames of reference or occupational positions, rather than creating new shared understandings and perspectives which can inhibit and constrain the possibilities for change' (p. 181). For both in-house and contract maintenance personnel, the stakes are significant. Some people want to provide more information than is strictly necessary to generate professional respect from other groups, but this intent can backfire with sharing more information simply leading production and management to have a higher degree of control over maintenance activity. Indeed, these balancing acts have an effect on the reliability of schedules. They impact the more or less "fictional" nature of schedules and thus planning reliability.

Paradoxically, standardization can result in the schedule becoming a 'fantasy plan' (Clarke 1999). When uncertainty is high, planning is no longer simply "a straightforward instrumental activity (a means to an end)" (Hayes and Hopkins 2014, p. 83); rather, the purpose of the plan becomes "asserting to others that the uncontrolled can be controlled" (Clarke 1999, p. 16). In this situation, symbolic plans represent a fantasy-in the sense of a promise that will never be fulfilled. The danger is that the plan itself takes on a life of its own and organizational effort is focused on managing the plan, rather than taking care of the socio-technical system itself. At risk are coordination, anticipation and management of uncertainties and finally organizational reliability.

\subsubsection{Heterogeneity in planners' professional practices}

The second organizational factor that affects the possibility of the schedule to act as a boundary object is the planners themselves. As 'articulation agents', planners play an important role in regulating these different practices, by accepting them or not. Planners intervene in the negotiation between other occupational groups through materialization of these negotiations on the schedules. The planners' group is heterogeneous and their vision of the work is not shared between members. In contrast to Vivian's professional practice, others simply wait for information to be provided to them and then see their role as that of a technician using planning software to organize content and produce a material object. Given this wide variation in approach, there is no homogeneous view of the planning function and it is searching for legitimacy. The way they define their professional role is important since it affects planning work, the skills involved, sensitivity to operations and, finally, the reliability of schedules. Depending on their skills and perception of the role, the planners will be more or less able to enroll other actors, especially maintenance and 
production, and to prevent the errors of misestimating and misunderstanding pointed out by Schulman (2012) (Fig. 3).

AQ4

\section{Fig. 3}

Model of schedules as BO for improved reliability

\begin{tabular}{|lll}
-- & Schedule's support for reliable performance & ++
\end{tabular}

\section{Schedule as material object}

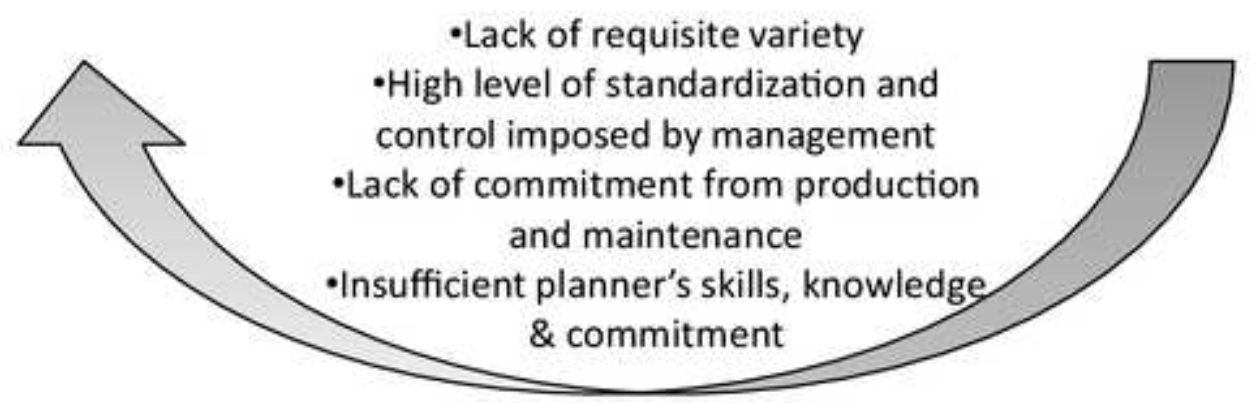

The challenge for organizational reliability is to maintain a focus on the various functions of the schedule linked to system performance in an environment of constant change. Weick and Sutcliffe (2015) explain that to maintain our ability to adapt to change, three things are needed: (1) "we have to trust the reports of others ...; (2) we have to report honestly so that others can use our observations to help them ...; (3) we have to maintain self-respect" (p. 37). HRO research has also highlighted that a problem is better solved when it migrates to those who have the greatest level of expertise in terms of the situation at hand. In this case, standardization linked to the increased level of control can reduce occupational autonomy. More importantly, problems no longer migrate to those with expertise but rather, those with authority. This can, in turn, lead to the disengagement of most experts, who can be expected to become less involved in managing the problem and so contribute to overall reliable performance. This issue is even more serious when planners do not or cannot act as "articulation agents". 


\section{Implications and conclusions}

Planning is ubiquitous in most large organizations and schedules are the physical embodiment of the notion that planned work is work that is under control. This study has shown that the role of a schedule goes far beyond that of simply an objective representation of time and task. Rather, the schedule acts as a boundary object that permits negotiation across five social worlds. The primary relationship is between maintenance and production. The varying views of the schedule between these two groups have an almost dualist quality. For maintenance, the schedule shows what they plan to do. For production, it shows what they will fail to do as production will be limited whilst the maintenance work proceeds. The process of schedule development, as fostered by the most effective planners, allows the joint narrative to be constructed so that cooperation is possible and maintenance work is completed whilst production impacts are managed. This interface is particularly critical in complex plants such as nuclear fuel processing where equipment failure can have catastrophic consequences.

A materialist view of a schedule would see it as a rigid representation of time and task, but viewing the schedule as a boundary object emphasizes its flexibility. HRO research has emphasized the extent to which diversity of views is valuable in ensuring reliability in complex systems. In the case of maintenance and production relationships, there is significant diversity and yet the flexibility in the process of schedule development and in the object itself provides a way in which diverse views can be resolved sufficiently for the plant to function with a high degree of reliability. The level of detail that a schedule should display, or its granularity, is a crucial object of negotiation. Questions of visibility and invisibility are decisive when it comes to boundary objects, since they embrace symbolic and political issues.

Our study reveals organizational factors that may disturb the required balance between the visible and invisible that supports schedules to act as boundary objects, thus enhancing organizational reliability. Firstly, management representatives see the schedule as an object of control over other actors and seek to increase their control by adding more details to the schedule. Taken to an extreme, this is likely to come at the expense of the flexibility that would allow the schedule to act as a boundary object between production and maintenance in particular. In contrast, Schulman (1993) describes what he sees as 'conceptual slack' in effective HROs where an organization seeks to have a variety of analytical perspectives regarding assumptions, theories and models of the technology or production processes in use. Reliability is achieved, not by organizational invariance and the strict following of fixed and formal rules and procedures, but by actively maintaining multiple views (from various departments) over site activities. Efforts to standardize processes of schedule development potentially endanger the multiple views currently in play.

Another factor that threatens the ability of the schedule to act as an effective boundary object is an excessive focus on production-in this case the use of the bureaucratic tool, 
on time delivery. This was originally intended to provide monthly production targets, but it has already taken on a greater degree of control over day to day operations and is effectively imposed on production as a daily production target. This system may once have acted as a boundary object between production and management, but at the time of the fieldwork was no longer functioning in this way, but rather, was a distinct threat to the boundary object status of the schedule by imposing the requirements of one social world on another.

The overall conclusions of the study regarding the role and status of maintenance schedules as boundary objects is provided in Table 4. While this has been generated based on a detailed study of one case, the way in which maintenance is planned and organized in the case study organization is not unique, but rather typical of the process industries overall. Use of contractors and division of work into preventative and corrective maintenance are common. For this reason, the model of effective planning and scheduling developed here is likely to have general applicability in such environments. Having said this, it should be noted that contractors have their own internal scheduling practices that have not been studied here. Research on maintenance planning could be extended with a multi-level study of planning that takes this extra complexity into account.

\section{Table 4}

Schedule as boundary object

\section{Schedule as material object}

Object showing time and task

Rigid-single literal meaning

Primarily a means of control of maintenance and contractors

Level of detail driven by desire for control

Imposes management/production requirements on maintenance/contractors

Invisible work made visible to increase control

Allocates tasks to specific groups

Does not deal well with unexpected events

Development process driven by rules and standard task requirements

Top-down communication of requirements to users

\section{Schedule as boundary object}

Object showing result of cross department negotiation

Flexible-multiple meanings exist

Not primarily a tool of control. Maintenance and contractors retain professional autonomy

Level of detail consistent with requirements for reliability

Makes cooperation possible without complete consensus

Invisible work made visible as necessary to understand complexity and tasks constraints

Supports negotiation at department interfaces

Supports discussion of multiple scenarios and consideration of uncertainty

Development process is a complex negotiation that is important in its own right as a means of building cross department understanding

Allows diverse and potentially conflicting needs to be discussed and co-ordinated 
Schedule as material object

Maintenance work seen as a cost to be minimized

Maintenance and contractors actors are reluctant to contribute to schedule development

Planners complete a largely clerical task

Does not support reliability in the face of uncertainty
Schedule as boundary object

Maintenance acknowledges contribution to reliability

Maintenance and construction actors are keen to contribute to schedule development

Planners have an important role in facilitating a complex process. They are 'reliable professionals'

Fosters anticipation and resilience, thus supporting reliability

Star's concept of boundary objects has proved useful in considering the relationships across a range of organizational boundaries in this complex system. This theoretical approach is underutilized in the safety research field and other key topics in safety that involve diverse professional groups such as crisis management, management of complex supply chains and studies of regulatory effectiveness could benefit from this approach.

\section{Acknowledgements}

We would like to thank the RESOH chair who funded this study and especially Stéphanie Gentil who actively contributed to the collection and analysis of empirical data in the field. For their helpful comments and advice, we want to express our gratitude to the members of the RESOH operational committee. Finally, a special thank you goes to our informants at NucCo for their friendship and patience over the last 3 years.

\section{References}

Baker J (2007) The report of the BP US Refineries Independent Safety Review Panel: http://sunnyday.mit.edu/Baker-panel-report.pdf

Bechky BA (2003) Object lessons: workplace artifacts as representations of occupational jurisdiction. Am J Sociol 109:720-752

Bourrier M (1996) Organising maintenance work at two American nuclear power plants. J Conting Crisis Manag 4:104-112

Bourrier M (2002) Bridging research and practice: the challenge of 'normal operations' studies. J Conting Crisis Manag 10:173-180 
Bucciarelli LL (1988) Engineering design process. In: Dubinskas FA (ed) Making time: ethnographies of high-technology organizations. Temple University Press, Philadelphia, pp 92-122

Chang A, Hatcher C, Kim J (2013) Temporal boundary objects in megaprojects: mapping the system with the integrated master schedule. Int J Project Manag $31: 323-332$

Clarke L (1999) Mission improbable: using fantasy documents to tame disaster. University of Chicago Press, Chicago

Corbin J, Strauss A (2014) Basics of qualitative research: techniques and procedures for developing grounded theory. Sage Publications, Thousand Oaks

Cullen (1990) The public inquiry into the piper alpha disaster. HMSO, London

Gautherau V, Hollnagel E (2005) Planning, control and adaptation: a case study. Eur Manag J 23:118-131

Hayes J, Hopkins A (2014) Nightmare pipeline failures: fantasy planning, black swans and integrity management. $\mathrm{CCH}$, Sydney

Journé B, Raulet-Croset N (2008) Le concept de situation: contribution à l'analyse de l'activité managériale dans un contexte d'ambiguïté et d'incertitude. M@n@gement 11:27-55

McInerney P (2001) Final report of the special commission of inquiry into the Glenbrook Rail Accident. The Commission, Sydney

Milch V, Laumann K (2018) Sustaining safety across organizational boundaries: a qualitative study exploring how interorganizational complexity is managed on a petroleum-producing installation. Cognition Technol Work 20:179-204 https://doi.org/10.1007/s10111-018-0460-8

Mintzberg H (1994) The rise and fall of strategic planning: reconceiving roles for planning, plans and planners. The Free Press, New York 
Oswick C, Robertson M (2009) Boundary objects reconsidered: from bridges and anchors to barricades and mazes. J Change Manag 9:179-193

Perrow C (1999) Normal accidents: living with high-risk technologies. Princetown University Press, Princetown

Roe E, Schulman PR (2016) Reliability and risk: the challenge of managing interconnected infrastructures. Stanford University Press, Stanford

Schulman PR (1993) The negotiated order of organizational rationality. Adm Soc 25:353-372

Schulman PR (2012) What in high reliability organizations (HRO) research might be useful in transmission planning? In Solan, David, Regional Electricity Transmission Planning in the West: Workshop Proceedings (September 1, 2012). Solan, D., Wilson, E., Kirschen, D., Hargrave, T., Lichtenstein, B., Schulman, P., Marcus, A., Koehler, D., Bearg, L. (September 2012). Energy Policy Institute. Available at SSRN: https://ssrn.com/abstract $=2269403$ s, pp 50-70

Star SL (2002) Infrastructure and ethnographic practice: working on the fringes. Scand J Inf Syst 14:6

Star SL (2010) This is not a boundary object: reflections on the origin of a concept. Sci Technol Hum Values 35:601-617

Star SL, Griesemer JR (1989) Institutional ecology, 'translations' and boundary objects: amateurs and professionals in Berkeley's Museum of vertibrate zoology. Soc Stud Sci 19:387-420

Starbuck WH, Farjoun M (2005) Organization at the limit: lessons from the Columbia disaster. Blackwell Publishing, Oxford

Suchman L (1987) Plans and situated actions: the problem of human-machine communication. Cambridge University Press, New York

Trompette P, Vinck D (2009) Revisiting the notion of boundary object. Revue 
d'anthropologie des connaissances $3: 3-25$

Vaughan D (1996) The challenger launch decision: risky technology, culture and deviance at NASA. University of Chicago Press, Chicago

Weick KE, Roberts KH (1993) Collective mind in organizations: heedful interrelating on flight decks. Adm Sci Q 38:357-381

Weick KE, Sutcliffe KM (2015) Managing the unexpected: assuring high performance in an age of complexity. Wiley, Hoboken

Windischer A, Grote G, Mathier F, Martins SM, Glardon R (2009) Characteristics and organizational constraints of collaborative planning. Cognition Technol Work 11:87-101

Yakura EK (2002) Charting time: timelines as temporal boundary objects. Acad Manag J 45:956-970 